\title{
Psychiatric treatment as anti-stigma intervention: Objective assessment of stigma by families
}

Amresh Shrivastava, Megan Johnston', Avinash De Sousa ${ }^{2}$, Sushma Sonavane ${ }^{2}$, Nilesh Shah ${ }^{2}$

Department of Psychiatry, Elgin Early Intervention Program for Psychosis, The University of Western Ontario, and Mental Health Resource Foundation, Mumbai, ${ }^{1}$ Department of Psychology, University of Toronto; Toronto, Ontario, Canada, ${ }^{2}$ Department of Psychiatry, Lokmanya Tilak Municipal Medical College and General Hospital, Mumbai, Maharashtra, India.

Address for the Correspondence:

Dr. Avinash De Sousa,

Carmel, 18, St. Francis Avenue, Off S.V. Road, Santacruz West, Mumbai - 400 054, Maharashtra, India. E-mail: avinashdes888@gmail.com

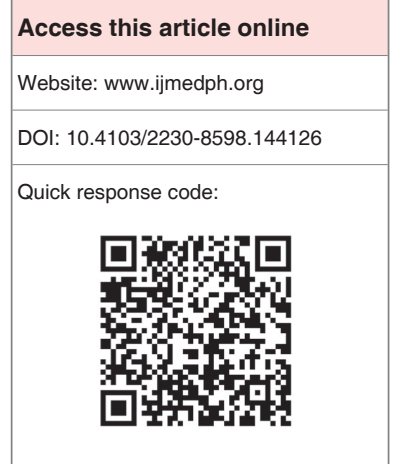

Background: Stigma related to mental illness is linked with suicide, violence, and lack of self-care, and thus should be treated as a clinical condition. For effective intervention, objective information about the impact of stigma is required in order to offer the best client-centered care. Objective: The present study seeks to answer the question of how stigma and discrimination are perceived to be experienced by their patient family members, to determine factors helpful for development of antistigma intervention programs. Materials and Methods: Three hundred family members of patients with schizophrenia provided their perceptions on aspects of stigma including anti-stigma interventions. There were two types of intervention strategies suggested (1) clinical measures and (2) public health measures. The predominant strategy was clinical measures which encompassed areas of availability of treatment, complete treatment, relapse prevention, and early intervention. Results: Furthermore, caregivers' emotional involvement $(64.8 \%)$ in treatment was seen as an important measure to reduce stigma. No social and public awareness is going to bring change in patients' lives if stigma is not addressed at an individual level in a client-centric manner. Conclusion: The responses of patient relatives clearly bring out this opinion when they suggest potential treatment components as intervention measures.

Key words: Caregivers, intervention, public health, stigma

\section{INTRODUCTION}

The presence of stigma surrounding mental illness is a universal dilemma. ${ }^{[1]}$ Conceptualization of stigma has changed over the years, yet it is typically thought of as an objective characteristic of an individual that leads to a negative valued social identity. ${ }^{[2]}$ No matter the definition, it is a barrier to treatment, as individuals experiencing mental health-related issues have a propensity to avoid seeking help for fear of social stigma and discrimination. ${ }^{[3]}$ Because of this, stigma has become a clinical risk factor associated with suicide, ${ }^{[4]}$ violence ${ }^{[5]}$ and lack of self-care, ${ }^{\left[{ }^{[6]}\right.}$ and therefore should be thought of as a clinical condition, ${ }^{[7]}$ and should be treated as such. The outcome of mental illness is dependent on the presence, understanding, and physical and emotional involvement of the individual's social support system. ${ }^{[8]}$ For effective intervention, objective information about the impact of stigma on the patient is required in order to offer the best client-centered care. Family members of patients are in an excellent position to provide adequate information on the effect of stigma, as they are often stakeholders and partners in care. ${ }^{[9]}$ It is well known that family members suffer the burden of being caregivers, in addition to a sense of loss and despondency. Since they are in such close proximity to mental illness, they frame their opinions of mental health through personal experience rather than hearsay. ${ }^{[10]}$ It has been shown that stigma causes discrimination due to prejudice ${ }^{[11]}$ further, stigma is related to various psychiatric disorders, ${ }^{[12]}$ and is in fact a predictive factor for outcome and level of functioning. ${ }^{[13]}$

Stigma associated with schizophrenia is particularly high in India. ${ }^{[14]}$ The authors have investigated patient's self-perception of stigma and found that stigma had a significant impact on the lives of these individuals, specifically low self-esteem and discrimination experienced in both family and work settings. ${ }^{[15]}$ Despite knowledge that stigma plays an important role in determining treatment outcomes and prevention, clinical services and programs have not been developed with specific 
consideration for stigma and anti-stigma interventions. ${ }^{[16]}$ The experiences and consequences of stigma felt by patients and their relatives has been thoroughly studied $;^{[17]}$ however, what is far less explored is how relatives perceive the impact of stigma on their patient family member. Operationalizing the subjective experiences felt by the relatives and the patients proves difficult, and runs the risk of misrepresentation. ${ }^{[18]} \mathrm{A}$ number of factors contribute to this difficulty, including, but not limited to, clinical state to perceive consequences, ability to express insights and judgments adequately, the attitudes of the family members, and their own personal fear and shame. ${ }^{[19]}$ As a result, an objective assessment of the impact of stigma is necessary for development of anti-stigma interventions. The present study does not examine whether family members face stigma themselves, but seeks to answer the question of how stigma and discrimination are perceived to be experienced by their patient family members, in order to determine which factors may be helpful for development of anti-stigma intervention programs.

\section{MATERIALS AND METHODS}

Participants were recruited through an educational seminar offered in Mumbai, India, for awareness entitled "Schizophrenia-carers and caregivers: Face to face" which was organized by a nongovernmental, voluntary organization in the field of mental health promotion. Participation in these seminars was free and sessions included lectures, workshops, and question-and-answer periods for the family members. These educational seminars were conducted every 3 months and regularly attended by 100-125 individuals for 4-hour sessions. During the educational sessions, questionnaires were distributed and consenting participants were asked to respond on a voluntary basis. 600 questionnaires were distributed during 10 sessions across a number of facilities in different parts of the city. Out of 600 questionnaires given out, 360 responses were received. Of these, 60 responses were excluded due to incomplete information, and therefore the data from 300 subjects were analyzed.

A semi-structured questionnaire was developed based upon the experience of the 'Open-the-Doors' program World Psychiatric Association (WPA) WPA initiative on stigma. ${ }^{[0]}$ This semi-structured questionnaire was designed to assess the relatives' perception of stigma and contained 10 questions, each with five to eight options to provide a yes or no response. Questions and potential responses were selected based upon the existing literature on stigma. ${ }^{[21]}$ Responses were classified into five categories:

1. Origin and nature of stigma,

2. Impact and experiences of stigma,

3. Anti-stigma interventions,

4. Views on mental illness, and

5. Hope for the future in management of stigma.

\section{RESULTS}

Detailed observations are provided in Tables 1 and 2. Of those who completed the questionnaires, almost all of the relatives $(99.7 \%)$ felt that the origin of the roots of stigma lies within unawareness about mental illness. Furthermore, $84.4 \%$ felt that the way families understand the illness and the problems their patients face was also a contributing factor to the origin. Many of the relatives felt that stigma originates from factors which are close to the patients, namely

\begin{tabular}{|c|c|c|}
\hline Factor and variables & $\begin{array}{l}\text { Frequency (\%) } \\
\quad(n=300)\end{array}$ & $\begin{array}{c}\text { 95\% Confidence } \\
\text { limit }\end{array}$ \\
\hline \multicolumn{3}{|l|}{ Origin and nature of stigma } \\
\hline Unawareness & $300(99.7)$ & 99.0 to 100.0 \\
\hline Familial & $254(84.4)$ & 80.3 to 88.4 \\
\hline Social & $239(79.4)$ & 74.8 to 83.9 \\
\hline $\begin{array}{l}\text { Attitude of relatives } \\
\text { cooperation }\end{array}$ & $227(75.4)$ & 70.5 to 80.2 \\
\hline Nature of illness & $225(74.8)$ & 69.8 to 79.7 \\
\hline Community & $206(68.4)$ & 63.1 to 73.6 \\
\hline Co-workers & $129(42.9)$ & 37.3 to 48.4 \\
\hline \multicolumn{3}{|l|}{$\begin{array}{l}\text { Experience and } \\
\text { consequences }\end{array}$} \\
\hline Low self-esteem & $210(69.8)$ & 64.6 to 74.9 \\
\hline Cannot cope with marriage & $138(45.8)$ & 40.1 to 51.4 \\
\hline Avoided due to illness & $184(61.1)$ & 55.5 to 66.6 \\
\hline $\begin{array}{l}\text { Overhearing offensive } \\
\text { comments }\end{array}$ & $126(41.9)$ & 36.3 to 47.4 \\
\hline Family & $116(38.5)$ & 33.0 to 43.9 \\
\hline Liabilities & $075(24.9)$ & 20.0 to 29.7 \\
\hline Isolation of patient & $136(45.2)$ & 39.5 to 50.8 \\
\hline Avoid disclosure & $101(33.6)$ & 28.2 to 38.9 \\
\hline Turned down in job & $081(26.9)$ & 21.8 to 31.9 \\
\hline Unaccepted in family & $097(32.2)$ & 26.9 to 37.4 \\
\hline Living alone & $080(26.6)$ & 21.6 to 31.5 \\
\hline $\begin{array}{l}\text { Pushed into unacceptable } \\
\text { social situations }\end{array}$ & $080(26.6)$ & 21.6 to 31.5 \\
\hline \multicolumn{3}{|l|}{ Anti-stigma interventions } \\
\hline Involvement & $195(64.8)$ & 59.4 to 70.1 \\
\hline Relapse prevention & $265(88.0)$ & 84.3 to 91.6 \\
\hline Complete treatment & $254(84.4)$ & 80.3 to 88.4 \\
\hline Better treatment & $252(83.7)$ & 79.5 to 87.8 \\
\hline Rehabilitation & $242(80.4)$ & 75.9 to 84.8 \\
\hline Educating & $243(80.7)$ & 76.2 to 85.1 \\
\hline Early identification & $223(74.1)$ & 69.1 to 79.0 \\
\hline Public involvement & $182(60.5)$ & 54.9 to 66.0 \\
\hline Reducing complications & $209(69.4)$ & 64.1 to 74.6 \\
\hline \multicolumn{3}{|l|}{$\begin{array}{l}\text { Relatives perception } \\
\text { of mental illnesses }\end{array}$} \\
\hline Dangerousness & $240(80.4)$ & 75.8 to 82.9 \\
\hline $\begin{array}{l}\text { Like any other medical } \\
\text { illness }\end{array}$ & $100(33.3)$ & 28.9 to 37.4 \\
\hline 'Mental weakness' & $180(60.0)$ & 53.9 to 65.0 \\
\hline 'Brain disease' & $080(26.6)$ & 21.6 to 31.5 \\
\hline Can lead to suicide & $205(68.3)$ & 63.4 to 74.6 \\
\hline Medication as a treatment & $254(84.4)$ & 80.3 to 88.4 \\
\hline Recovery of patients & $182(60.5)$ & 54.9 to 66.0 \\
\hline Extending help & $198(65.8)$ & 60.4 to 71.1 \\
\hline $\begin{array}{l}\text { Style of information of } \\
\text { relatives: Say it is mental } \\
\text { illness needing care }\end{array}$ & $220(73.1)$ & 68.0 to 78.1 \\
\hline
\end{tabular}




\begin{tabular}{|c|c|c|}
\hline Factor and variables & $\begin{array}{l}\text { Frequency (\%) } \\
\quad(n=300)\end{array}$ & $\begin{array}{c}95 \% \text { Confidence } \\
\text { limit }\end{array}$ \\
\hline \multicolumn{3}{|l|}{ Nature of stigma } \\
\hline Social & $239(79.4)$ & 74.8 to 83.9 \\
\hline Familial & $254(84.4)$ & 80.3 to 88.4 \\
\hline \multicolumn{3}{|l|}{ Causes of stigma } \\
\hline Unawareness & $300(99.7)$ & 99.0 to 100.0 \\
\hline Nature of illness & $225(74.8)$ & 69.8 to 79.7 \\
\hline \multicolumn{3}{|l|}{$\begin{array}{l}\text { Form of stigma } \\
\text { (Category-I) }\end{array}$} \\
\hline Low self-esteem & $210(69.8)$ & 64.6 to 74.9 \\
\hline $\begin{array}{l}\text { Cannot cope with } \\
\text { marriage }\end{array}$ & $138(45.8)$ & 40.1 to 51.4 \\
\hline \multicolumn{3}{|l|}{$\begin{array}{l}\text { Form of stigma } \\
\text { (Category-II) }\end{array}$} \\
\hline Avoided due to illness & $184(61.1)$ & 55.5 to 66.6 \\
\hline $\begin{array}{l}\text { Overhearing offensive } \\
\text { comments }\end{array}$ & $126(41.9)$ & 36.3 to 47.4 \\
\hline \multicolumn{3}{|l|}{ Attitude of relatives } \\
\hline Extending help & $198(65.8)$ & 60.4 to 71.1 \\
\hline Cooperation & $227(75.4)$ & 70.5 to 80.2 \\
\hline \multicolumn{3}{|l|}{$\begin{array}{l}\text { Anti-stigma } \\
\text { measures- I }\end{array}$} \\
\hline Involvement & $195(64.8)$ & 59.4 to 70.1 \\
\hline Public involvement & $182(60.5)$ & 54.9 to 66.0 \\
\hline \multicolumn{3}{|l|}{ Sources of stigma } \\
\hline Community & $206(68.4)$ & 63.1 to 73.6 \\
\hline Family & $116(38.5)$ & 33.0 to 43.9 \\
\hline Co-workers & $129(42.9)$ & 37.3 to 48.4 \\
\hline \multicolumn{3}{|l|}{$\begin{array}{l}\text { Style of information } \\
\text { of relatives }\end{array}$} \\
\hline $\begin{array}{l}\text { Say it is mental } \\
\text { illness needing care }\end{array}$ & $220(73.1)$ & 68.0 to 78.1 \\
\hline \multicolumn{3}{|l|}{ Impact of stigma } \\
\hline Liabilities & $75(24.9)$ & 20.0 to 29.7 \\
\hline Isolation of patients & $136(45.2)$ & 39.5 to 50.8 \\
\hline \multicolumn{3}{|l|}{ Consequences } \\
\hline Avoid disclosure & $101(33.6)$ & 28.2 to 38.9 \\
\hline Turned down in job & $81(26.9)$ & 21.8 to 31.9 \\
\hline Unaccepted in family & $97(32.2)$ & 26.9 to 37.4 \\
\hline Living alone & $80(26.6)$ & 21.6 to 31.5 \\
\hline $\begin{array}{l}\text { Pushed into } \\
\text { unacceptable social } \\
\text { situations }\end{array}$ & $80(26.6)$ & 21.6 to 31.5 \\
\hline
\end{tabular}

social factors $(79.4 \%)$, particularly overhearing offensive comments (41.9\%), and the attitudes of family members (75.4\%). Moreover, $74.8 \%$ of relatives felt that stigma originates from the very nature of the illness itself; $68.4 \%$ thought community factors and $42.9 \%$ thought co-workers were seen to contribute to the origin of stigma.

With respect to experiences and consequences, according to their relatives, the majority of patients suffer low self-esteem (69.8\%), find it difficult to handle marriage $(45.8 \%)$, and suffer from avoidance $(61.1 \%)$ and social isolation $(45.2 \%)$ often because they view themselves as liabilities $(24.9 \%)$ and often get turned down for jobs $(26.9 \%)$. They remain unaccepted in the family $(32.2 \%)$, and are often forced to live alone $(26.6 \%)$ or are pushed into unacceptable situations $(26.6 \%)$, such as abuse, denial of food and shelter, homelessness and violence.

In addition to providing information on their perception of how stigma affects their patient family members, relatives also suggested potential intervention strategies to deal with stigma in a positive and defined way. There were two types of intervention strategies suggested:

1. Clinical measures, and

2. Public health measures.

The predominant strategy was clinical measures which encompassed areas of availability of treatment, complete treatment $(84.4 \%)$, relapse prevention $(88.0 \%)$ and early intervention $(74.1 \%)$. Furthermore, relatives felt that caregivers' emotional involvement $(64.8 \%)$ in treatment is also an important measure to reduce stigma. Among the public health measures, awareness (99.7\%), education $(80.7 \%)$, and involvement of people $(60.5 \%)$ are combatants of stigma.

The way relatives themselves perceive and understand the mental illness is also an important aspect. The majority of relatives felt that perceived dangerousness $(80.4 \%)$ is the prime cause of discrimination of patients in society and also felt that mental illness can often lead to suicide $(68.3 \%)$. They believe that medication as a treatment $(84.4 \%)$ is the best option, and recovery of the patient is possible $(60.5 \%)$. They did not, however, feel that mental illness was akin to other physical illnesses $(33.3 \%)$ or disease of the brain (26.6\%), but rather felt that mental illness was the product of a weak mind $(60.0 \%)$. Besides all of the disappointing opinions, it is clear that a large number of relatives them felt that they were the best option to extend help (65.8\%), and cooperation $(75.4 \%)$, as well as the best way to communicate $(73.1 \%)$ about illness to others.

\section{DISCUSSION}

The stigma of mental illness has been well established as a complicating feature of psychiatric disorders which subsequently affects treatment outcome. ${ }^{[16]}$ Stigma is especially prominent around individuals with schizophrenia ${ }^{[22]}$ and has been demonstrated as a clinical risk factor for recovery and treatment seeking. ${ }^{[12]}$ Not surprisingly, in addition to affecting the patient, stigma also affects relatives and care givers who often suffer sufficient burden. ${ }^{[6]}$ Developing intervention strategies to deal with stigma has predominantly focused on creating awareness and sensitizing people who can make a difference in the lives of the patient, such as caregivers and clinicians. ${ }^{[23]}$ As such, both broad-based and specific-focused interventions have been used. The argument to develop these intervention methods has been based upon experiences and opinions of both the patient and his or her family. ${ }^{[20]}$ The fight against stigma is a comprehensive one. Thus far, the issue of stigma has been approached through a public health perspective $;^{[7]}$ however, a clinical approach is necessary, yet has not been discussed for prevention and intervention of stigma. ${ }^{[19]}$ 
Consistent with previous literature concerning patient self-stigma, ${ }^{[24]}$ the present study reveals that the overwhelming majority of patient relatives believed that stigma originated from unawareness and the attitudes of people in society, as well as the family. Thus, it appears that the perceptions of relatives' experiences with stigma are no different from what has been found regarding patients self-reports. ${ }^{[15]}$ Additionally, responses of relatives also show a high prevalence of stigma from societal and familial factors which consequently result in discrimination, low self-esteem, isolation, avoidance, and being faced with unacceptable social situations. The most significant finding of our study is the opinions of relatives' with respect to anti-stigma intervention strategies. More than $80 \%$ of responders said that issues related to treatment are far more important than the lack of awareness. Lack of awareness alone is not responsible for keeping patients away from treatment, but it is the fear of being labeled as mentally ill that is the greatest contributing factor to treatment outcome. ${ }^{[16]}$ A number of studies have consistently shown that abnormal behavior and perceived dangerousness are two of the main causes of stigma. ${ }^{[25]}$ This means that if dangerous behavior is a cause of stigma, the answer cannot be merely increasing awareness in the society, there needs to be a clear demonstration that such perceptions are baseless.

While they do opine that dealing with unawareness and public involvement is necessary, they bring about the unique factor of treatment of mental disorders as an anti-stigma intervention. ${ }^{[23]}$ The present study clearly exemplifies what the relatives of a patient believe about dealing with stigma. In their opinion, it is important to focus on factors which may produce a barrier to successful treatment besides simply emphasizing targeting the lack of awareness in various groups, and dealing with attitudes of people, professionals and caregivers. Particularly delay in treatment leads to an increased risk for non-compliance and poor outcome. These two factors increase the risk for chronicity and social impairments which are poorly responsive in treatment. ${ }^{[8]}$ Frequent hospitalizations lead to isolation thus perpetuating the impact of stigma, therefore relapse prevention program development and implementation in a clinical setting is helpful. Several measures are mentioned related to the fight against stigma; enhancing access to care, relapse prevention, and early identification are some of these measures. Moreover, specific measures have been defined as anti-stigma interventions, such as complete treatment, relapse prevention, early intervention, rehabilitation and facilities for treatment. ${ }^{[26]}$ Based on our findings, we propose that several other measures need to be utilized and scientifically evaluated. Besides public health measures, there is a need to include:

1. Intervention in clinical settings;

2. Improved access to care by increasing and developing new services;

3. Modified clinical programs as per the needs of the patients and relatives, not developed as per "felt-needs" of policy makers;

4. Involvement of relatives as stakeholders in practical terms;

5. Assured continuity of care and risk-management, and finally

6. Development of advocacy and awareness groups to manage the lack of awareness and negative attitudes.
No social and public awareness is going to bring change in patients' lives if stigma is not addressed at an individual level in a patientcentric manner. The responses of patient relatives clearly bring out this opinion when they suggest potential treatment components as intervention measures. Both clinical and public health approaches will have to be employed at the congruently to reinforce each others' outcome.

\section{REFERENCES}

1. Corrigan PW, Watson AC. Understanding the impact of stigma on people with mental illness. World Psychiatry 2002;1:16-20.

2. Yang LH, Kleinman A, Link BG, Phelan JC, Lee S, Good B. Culture and stigma: Adding moral experience to stigma theory. Soc Sci Med 2007;64:1524-35.

3. Corrigan PW. How stigma interferes with mental health care. Am Psychol 2004;59:614-25.

4. Griffiths KM, Crisp DA, Jorm AF, Christensen H. Does stigma predict a belief in dealing with depression alone ? J Affect Disord 2011;132:413-7.

5. Torrey EF. Stigma and violence: isn't it time to connect the dots ? Schizophr Bull 2011;37:892-6.

6. Tsang HW, Tam PK, Chan F, Cheung WM. Sources of burden on families of individuals with mental illness. Int J Rehabil Res 2003;26:123-30.

7. Sharac J, McCrone P, Clement S, Thornicroft, G. The economic impact of mental health stigma and discrimination: A systematic review. Epidemiol Psychitar Soc 2010;19:223-32.

8. Tol WA, Barbui C, Galapatti A, Silove D, Betancourt TS, Souza R, et al. Mental health and psychosocial support in humanitarian settings: Linking practice to research. Lancet 2011;378:1581-91.

9. Awad AG, Voruganti, LN. The burden of schizophrenia on caregivers: A review. Pharmacoeconomics 2008;26:149-62.

10. Caqueo-Urízar A, Gutiérrez-Maldonado J, Miranda-Castillo C. Quality of life in caregivers of patients with schizophrenia: A literature review. Health Qual Life Outcomes 2009;7:84.

11. Van Brakel WH. Measuring health related stigma: A literature review. Psychol Health Med 2006;11:307-34.

12. Corrigan, $P W$, Wassel $A$. Understanding the influence of stigma on mental illness. J Psychosoc Nurs Ment Health Serv 2008;46:42-8.

13. Pinto-Foltz MD, Logsdon MC. Stigma towards mental illness: A concept analysis using postpartum depression as an exemplar. Issues Ment Health Nurs 2008;29:21-36.

14. Kulhara $P$, Shah $R$, Aarya KR. An overview of Indian research in schizophrenia. Indian J Psychiatry 2010;52(Suppl 1):S159-72.

15. Shrivastava A, Johnston ME, Thakar M, Shrivastava S, Sarkhel G, Sunita I, et al. Origin and impact of stigma and discrimination in schizophreniapatients' perception: Mumbai study. Stigma Res Action 2011;1:67-72.

16. Markowitz FE, Angell B, Greenberg JS. Stigma, reflected appraisals and recovery outcomes in mental illness. Soc Psychol Quat 2011;74:144-65.

17. Livingston JD, Boyd JE. Correlates and consequences of internalized stigma for people living with mental illness: A systematic review and metaanalysis. Soc Sci Med 2010;71:2150-61.

18. Ben Zeev D, Young MA, Corrigan PW. DSM-V and the stigma of mental illness. J Ment Health 2011;19:318-27.

19. Stuart H, Koller M. Milev R. Inventories to measure the scope and impact of stigma from the perspective of those who are stigmatized - consumers and family versions. In: Arboleda-Flórez J, Sartorius N, editors. Understanding the stigma of mental illness: Theory and interventions. Toronto: Wiley and Sons, Ltd; 2008. p. 193-204.

20. Sartorius N, Schulze H. Reducing the stigma of mental illness: A report from the Global Programme of the World Psychiatric Association. New York: Cambridge University Press; 2005.

21. Murthy SR. Perspectives on the stigma of mental illness. In: Okasha A, Stefanis CN, editors. Stigma of mental illness in the third world. Geneva: World Psychiatric Association; 2005. p. 112.

22. Corrigan PW, Morris SJ, Micheals PJ, Rafacz JD, Rusch N. Challenging the public stigma of mental illness: A Meta-Analysis of outcome studies. Psychiatr Serv 2012;63:963-73. 
23. Warner R. Implementing local projects to reduce the stigma of mental illness. Epidemiol Psychiatr Soc 2008;17:20-5.

24. Karidi MV, Stefanis CN, Theleritis C, Tzedaki M, Rabavilas AD, Stefanis NC. Perceived social stigma, self-concept, and selfstigmatization of patient with schizophrenia. Compr Psychiatry 2010;51:19-30.

25. Vahabzadeh A, Wittenauer J, Carr E. Stigma, schizophrenia and the media: Exploring changes in the reporting of schizophrenia in major U.S. newspapers. J Psychiatr Pract 2011;17:439-46.

26. McQuaid JR, Marx BP, Rosen MI, Bufka LF, Tenhula W, Cook H, et al.
Mental health assessment in rehabilitation research. J Rehabil Res Dev 2012;49:121-38.

How to cite this article: Shrivastava $A$, Johnston $M$, Sousa AD, Sonavane S, Shah N. Psychiatric treatment as anti-stigma intervention: Objective assessment of stigma by families. Int J Med Public Health 2014;4:491-5.

Source of Support: Nil, Conflict of Interest: None declared. 